\title{
Online Teaching And Learning In A Graduate Course In Nursing Education
}

\author{
NS Gwele \\ $\mathrm{PhD}$. \\ School of Nursing \\ University of Natal-Durban
}

\section{Abstract}

Information technology has a potential to be the answer to one of Africa's most pressing problems- providing education to a number of geographically dispersed learners, who currently have to leave their countries for a number of years in order to pursue their studies elsewhere. The School of Nursing at the University of Natal launched an online graduate course in nursing education at the beginning of the year $\mathbf{2 0 0 0}$ for the first time as part of a masters degree programme.

A number of lessons have been learned from this experience. Firstly, it took too long to arrive at 'closure' on discussion of any one particular theme. There seemed to be a perpetual feeling of never "completing" teaching/learning tasks. Ordinarily, in a face-to-face ( $f 2 f)$ classroom, a particular theme or topic is scheduled for a particular lecture period. More often than not, whether clarity and/or resolution has been attained, the discussion moves on to the next theme, or topic. This has not been easy to do in computer mediated communication (CMC). The students' contributions, however, seemed more thought out and more focused than had been the case in the $\mathrm{f} 2 \mathrm{f}$ classes. Secondly, the essentiality/importance of structure became apparent very early. After an initial tentative and slow start, once the students felt comfortable with the computer "classroom", the bulletin board was flooded with messages, necessitating re-thinking the original structure.

\section{Introduction}

\section{"No where else in the world is the idea of distance education more ideal as in Africa."}

No where else in the world is the idea of distance education more ideal as in Africa. Poor postal services have greatly affected both the efficiency and effectiveness of traditional distance education programmes in this continent. Information technology has a potential to be the answer to one of Africa's most pressing problems-providing education to a number of geographically dispersed learners, who have had to leave their countries in order to pursue their studies elsewhere. It is not really known, how many of those who leave their countries to study elsewhere, ultimately return to their countries of origin on completion of those studies. It can be argued, however, that quite a few do not, with resultant loss in human capital in a number of countries across the continent.

Furthermore, the cost of higher education for the returning adult African student is high. Most have the added responsibility of paying for their children's education. Leaving their jobs in pursuit of further and higher education is often not seen as a viable option. Computer mediated communication (CMC) provides a viable alternative for this group of so-called 'non-traditional' learners. Westwell (1999: 1) highlights that "CMC has a potential to overcome what have been 'historically two of the major technical barriers to human communication, that is, time and space". Whether or not Africa exploits this unique environment for teaching and learning will depend on (a) accessibility, financially and technologically, (b) attitudes of teachers toward change and (c) willingness on the part of the teachers to share control and responsibility for teaching and learning with the learners. For most educational institutions, however, adopting CMC is no longer a matter of willingness on the part of the teacher, but a reality which can no longer be ignored. Declining student enrollment in higher education in stitutions makes distance education an imperative rather than a choice.

\section{The context}

In 1996 a masters degree programme in progressive education for health professionals was implemented at the University of Natal's (UND) School of Nursing. The aim of the program is to prepare specialist educators in health professions, who would be able to design, implement and evaluate community and problem-based learning programmes. This programme was initiated with financial assistance, including student bursaries, from the Kellogg Foundation. Ability to study full-time was a requirement. During the first two years of implementation, we had no problem recruiting and selecting students. When foreign fund- 
ing dried up, the numbers of admissions dropped. However, the programme was still in demand. Applicants requested that we examine the possibility of parttime study. The idea of offering the programme online was born. Rebholz, (1995) in reference to a continuing education programme in engineering, raises an important point in observing that not all courses are amenable to computer conferencing. The course progressive education for health professionals was seen as appropriate for CMC. Critical discussion of literature related to the content area is the major focus of whole programme. Besides, the face-to-face (f2f) classes in the programme had placed emphasis on cooperative learning as well self-directed learning from the programme's inception.

None of the teaching staff in the School of Nursing, however, were familiar with online teaching and learning. As the programme coordinator and facilitator I enrolled with the University of London's Institute of Education on a course in online education and training (OET99/ $00)$. Being an OET student provided me with first hand experience as an online learner, while at the same time vicariously learning about teaching online. Experiences gained as a learner were invaluable in helping me anticipate and 'understand' some of the problems encountered during implementation of the online course at UND.

The candidate pool for the course Progressive Education for Health Professionals II are educators in the health professions who have a teaching qualification. In addition, the students must have taken and passed courses in foundations of educational philosophy, curriculum development and foundations of educational psychology. The course involves an in-depth study of global trends in the education of health professionals. Furthermore, contemporary approaches to curriculum are dealt with, specifically those approaches that place emphasis on experiential education, including: community-based education (CBE), problem-based learning ( $P B L)$, casebased learning (CBL) and service learning. The course ends with a brief overview of student assessment and evaluation in professional education.

\section{Intended learning outcomes}

On completion of this course the learners should be able to:

- Analyse the views of the World Health Organization (WHO) and the International Council for Nurses (ICN) on undergraduate education in the health professions in relation to national health and education policies.

- Examine the place of experiential education and selected experiential learning theories in the education of health professionals.

- Critically analyse prevailing discourses and theories of reflective teaching practice.

- Demonstrate understanding of nontraditional approaches (PBL, CBE, CBL, \& service learning) to curriculum in the health professions.

- Select and set assessment and evaluation strategies congruent with active teaching/learning approaches as well as intended learning outcomes.

- Evaluate the role of professional regulatory bodies in nursing and midwifery education.

\section{Teaching and learning experiences}

This course is offered online through WebCT.

- Except for teaching practice, online conferencing is the only delivery mode.

- Group discussions, Case-Studies and various forms of computer mediated communication for independent learning are used. (Example: Learning Logs and/ and a Reflective Teaching Practice record)

Hiltz (1995) and Turoff (1995) warn designers of CMC courses about the volume of messages coming through the conference areas each day and/or week. According to Hiltz with classes of about 20 to 30 students, one should expect at least about 100 messages a week. This might lead to information overload for both the students and the moderator. To which she (Hiltz, 1995: 5) recommends that the "instructor must establish regular rhythms and schedules, based on dividing the course into modules which last a week, ... or half, or two weeks each so that participants can plan ahead in terms of when they will need to sign online, when work will be due, and so that the groups move through the topics in an orderly manner". Similar views were echoed by Pincas (1999). Hence, it was decided to breakdown the themes of the course into weekly or two weekly sessions depending on the depth and breadth of the topic for discussion.

\section{Assessment and evaluation}

Astin (1993: 233) asserts that "A critically important task in any assessment project is to define the relevant outcomes and to choose the methods for assessing them". He further argues that values underpin assessment practices, not only in terms of what we decide to assess, but also in how we decide to assess it. According to him, talent development is the core of educational practice and that assessment should aim at providing feedback for both the learner and the teacher. Contextual issues however, demand that both formative assessment, whose main aim is to promote learning and development, and summative as sessment, aimed mainly at making decisions regarding failure and/or success are essential components of the higher education assessment system. Hence, for the present course both formative and summative assessment were used Formative assessment consisted of individual and group feedback posted in the bulletin board weekly or during the course of a week's activities. Summative evaluation on the other hand consisted of two assignments and an end of the semester open-book conventional examination.

The choice of an open-book conventional examination rather than an electronic examination was based on the paucity of "guidelines" and or discourse on the use of open-ended questions, especially those requiring argumentation in CMC. Most of the available exemplars found used multiple choice questions. Lamenting on the US higher education institutions' overreliance on multiple choice examinations, Astin (1993:55) contended that perhaps, the ease with which such examinations can be administered and scored, together with the ease with which they yield quantitative scores, might be a contributing factor to their popularity. He notes, however, that the multiple choice test "is an inappropriate technology for assessing many types of creative outcomes that are highly valued not only by the academic community but also in later life". Likewise, the type of content dealt with in this course, as well as the expected learning outcomes do not lend themselves very well to multiple choice examinations.

\section{Course structure}

Literature attests to the importance of structure in curriculum design. Various software programmes such as First Class, Merlin, WebCT etc, offer different facilities for organisational structure in CMC . My experience with online learning as an OET99/00 student indicated that I would need various facilities or "learning spaces" in order to ensure a manageable course structure for both myself and the students. However, my institution did not have First Class- the only conferencing system with which 1 was familiar. The available system at the University of Natal is WebCT, hence most of the facilities which I believed I needed 
in order to create a workable structure for the course were just not available. With the help of an experienced computer-based instructional design expert from the University's Information Technology Department, we planned to use a (a) main bulletin board, (b) private mail facility, (c) chat facility, (d) course content area, (e) calendar ( $f$ ) student records area and $(\mathrm{g})$ whiteboard.

\section{The main bulletin board}

The main bulletin board is used as a main discussion forum. It is the only space in which group work is carried out. Overtime it became clear that this was not enough. Hiltz (1995: 2) maintains that "minimally acceptable technology foundation is a conferencing system that allows the instructor to set up different conferences for different purposes...". The other side to provision of separate conference areas for different purposes is that just how much is not too much. One of the students in the OET course $(99 / 00)$ identified navigability as one of the essential features for a conferencing system. In CMC context, navigability is dependent both on the number and uses of conference areas. It is clear that too many conference areas might be too confusing to students as was the case with the above student who stated that "it (navigation in First Class) is not difficult, however, the constant disappearing into different layers without being sure where you'll come out is annoying". An observation with which I concur.

The latter problem, however, was not an issue with the designing of the present course. The major problem encountered was the lack of a facility to set up different "learning spaces" for different purposes. Hence, the main bulletin became clogged with masses of information too soon. Needless to say that the moderator's inexperience with WebCT was a problem. Perhaps it is possible to retrieve only the section of dialogue you want to work with in WebCT, but so far it has only been possible to retrieve either unread or new messages, or all the messages from the beginning of the course. This is extremely frustrating. The main bulletin is currently functioning as a the notice board, the discussion area, as a well as a "social" gathering area.

\section{Private mail}

The availability of a private mail facility in CMC cannot be taken for granted. Anderson (1996a: 12) based on study examining student and faculty perceptions about the importance of various features of an online course offered at Massey University College of Education came to the conclusion that "Email lists have proven to be a valuable pedagogi- cal tool and appear to have been critical in helping students collaborate in learning and to establish support mechanisms...". Private mail became invaluable during the course of the semester. It was used mainly for contacting individual students, either to respond to individual questions, provide feedback, as well as to encourage participation for those students who tend to disappear from the "screen" from time to time. Also, students use this facility to communicate with each other and the course moderator.

An adjunct use for the private mail facility arose out of a need to establish small groups. The idea was really to encourage "communities of learners" where the small groups of four students would work together on various course projects without the other group being able to access other groups' work-in-progress. At the end of the allotted time for completion of small group tasks, groups were expected to post their contributions in the main bulletin board.

\section{Chat facility}

The initial plan was to use the synchronous communication facility mainly for meetings rather than learning. The idea was that once a month we would schedule a "virtual" meeting. The items for discussion at this meeting would be decided by both the moderator and the students. That is, once a date for a meeting was scheduled each student was allowed to post an item for inclusion in the agenda on the main bulletin board. Selection of items for discussion at the meeting was solely based on the number of students interested in them. Items of individual student interest were dealt with through the private mail facility.

\section{The whiteboard}

This is an area where every course participant could scribble social, educational and administrative issues. The plan was to use the whiteboard both formally and informally. For instance, I thought that this area would be perfect for notices regarding scheduled chat sessions, wishing someone a happy birthday, reminders about assignment due dates and so on. As will be revealed later in this paper, this was the part of the course which was a total 'fiasco', and continues to be.

\section{Experiences with online teaching and learning}

Although this section focuses mainly on difficulties encountered with $\mathrm{CMC}$, there were some positive experiences as well. Specifically, the ability to think through what a student says and be able to offer well thought feedback rather than reactionary feedback as is likely to occur in f2 $f$ situations. Similarly, the permanency of both the moderator's contributions as well as the students' contributions make it possible for the moderator to retrieve the discussion transcripts and evaluate these both in terms of quality and quantity in order that improvements based on learning from this course can be made in designing and delivering the same or other courses online. There seems to be no paucity of literature on the positive aspects of CMC. Consequently, a decision was made to highlight those areas which were more problematic than pleasant as well as how they were dealt with.

\section{Design and structure}

The essentiality/importance of structure became apparent very early in the course. More than 10 years ago, studies on effective schools in the US revealed that more often than not, it is not the substantive aspects of the curriculum, but its organisational structure which makes a difference in terms of effective teaching and learning. This applies even more so to online courses. In online teaching/learning such a view is supported by Hiltz (1995) She identifies richness of media, timely responsive. ness, organisation and interaction as the four basic principles for CMC. Sadly, however structural design in education, especially computer mediated teaching and learning, is usually compromised by administrative and infra-structural issues. University courses do not run forever, there is a limit to how long a semester or a term lasts. The quality of software available depends both on financial constraints as well as what the University's IT department staff are familiar with.

As mentioned earlier WebCT had only one conference area for all asynchronous discussions including posting notices. This conference area became overloaded very fast. The students just simple did not use the whiteboard, which was initially targeted for notices. Messages posted in the whiteboard remained unread until the system automatically erased them. A plan had to be made. Private mail was then used to divide the students into groups of four each. They were then required to work in these small groups before posting their contributions as a group in the main bulletin. The moderator was a non-participant member of each group. This improved the problem of the volume of messages in the main bulletin as well as 
focusing the discussion on scheduled themes and/or topics.

Most literature on CMC supports the need to include a week or two in the beginning for introducing students to this mode of delivery. In the case of Smith (1999) among other things, orientation activities included information on both the concept of $\mathrm{CMC}$, and the teaching/ learning process chosen for the course on leadership development at The Open Polytechnic of New Zealand. The OET99/ 00 course placed emphasis on familiarising students with First Class as well as course structure. However, issues such as norms for participation, teacher and learner expectations regarding both the quantity and the quality of participation were not really discussed during the orientation period. Hence, as the course progressed, problems related to nonparticipation, over-participation, as well as what exactly is meant by participation were raised.

For the present course students were invited early in the programme to discuss participation norms, netiquette, as well as familiarise themselves with WebCT. To my disappointment, however, the students just simple did not respond to this invitation. Hence the course progressed without ever coming to a decision about what is "acceptable" behaviour for the class participants, what would be considered rude and what would not be, what would really count, the quantity or the quality of participation. A mistake for which both the moderator and the students paid dearly in the end. For instance, two months into running of the course, some of the students voiced concern that the weekly individual and group activities were not graded. Yet, some felt that grading "class" discussions would lead to increased levels of anxiety, in an environment that they were not very familiar with. Needless to say, these concerns could not be accommodated this late in the semester. Another course is planned for online delivery in the second semester. For the new course both quality and quantity of participation will be taken into consideration in making examination entry decisions.

\section{The teaching and learning process}

Paulsen (1995) identifies a number pedagogical strategies amenable to online teaching and learning. He/she distinguishes between (a) one to many, (b) one to one and (c) many to many strategies. The one to many strategies are no more than the traditional teacher-directed classroom activities found in the face-to-face (f2f) teaching/learning environment, whereas one to one strategies refer to such teaching/learning processes as research supervision and contract learning. The many to many pedagogical strategies on the other hand, include a number of active learning and student-centered strategies associated with cooperative learning, communities of learning and so on.

For the graduate course in nursing education we chose the many to many and the one to one strategies. We believed that both approaches were congruent with intended learning outcomes. A number of lessons have been learned from this experience. These were related to (a) participation and/or interaction, (b) quality of students' contributions, and (c) lack of closure and isolation. A brief discussion of each of these problems follows.

\section{Participation and/or Interaction}

Some students took too long to get into the rhythm of the discussion. This required frequent prompting from the moderator in the form of individual messages reminding them of the need to be fully engaged in the class activities. When the students finally participated, it became clear that in fact they were not talking to each other but along each other. This occurred even when they were required to respond to each others contributions. Student A would comment on student B's message and student $B$ would not say anything either in agreement or disagreement. This prompted a long "lecture" on the importance of talking to each other, reminding the students of just how beneficial talking together and to each other had been in the $f 2 f$ classes.

Henri (cited in Anderson (1996b: 2) states that ".. Most authors equate the interactive process with participation: when they report on an experiment in training with $\mathrm{CMC}$, they imply that to measure participation is to measure interaction. Thus it is presumed that any and all messages recorded in a teleconference are interactive...". Anderson (1996b: 2) rightly responds that "However, this assumption is not always correct". The students in the present class, although participating, were certainly not interacting. According to Anderson a number of factors foster interaction in an online course. These include (a) programme wide factors, (b) online activities, (c) staff teaching skills, and (d) student skill and attitude. All of these factors were seen to operate in the course discussed in this paper.

Programme wide issues were related to the fact that this was a second year course of a traditionally f2f programme. All of the previous year's courses had been offered f2f with the same group of students. Furthermore, other programme demands such as working on research proposals might have prevented students from paying attention to what their colleagues were saying and just saw participation as a "chore" which they just had to do in order to move on to the next important activities in their student lives, whatever those might have been.

The online activities themselves were designed to encourage student-student interaction. It seems that this was not enough. As Wells (cited in Anderson, 1996b: 2) notes "where student-to-student interaction was encouraged but not required (either in the form of a mandatory number of messages per week or formal group work), strictly voluntary usage was considerably lower than course designers had anticipated". Although group activities were required in the present course, initially, the moderator had no way of monitoring the group in the process of learning and working on the group project. Students simple worked out their own strategy to "meet" and work on the assignment. Only the finished "group" project was posted in the main bulletin. The only means of monitoring interaction was through the required responses to each other's messages. Structural changes as well as the emphasis on student-to-student discussion helped improve interaction overtime.

\section{Quality of Student Contributions}

Initially students' contributions were extremely superficial and uncritical. This is contrary to what has been said about the quality of students' contributions in CMC. There seems to be a tacit understanding in some of the literature on CMC that asynchronous discussion will necessarily lead to reflective thinking and improved quality of learning and therefore, student contributions (Hiltz, 1995; Kimball (date unknown: 7). For instance Kimball states that "Because participants have more time to observe what others have said, reflect on the ideas, and compose their own thoughts, they can express themselves more clearly". This did not automatically happen in the present course.

The quality of students' contributions is to a great extent a function of teaching skills, student skills and attitude towards learning. $\mathrm{CMC}$ teaching and learning skills take time to develop. Bennett (cited in Westwell, 1999: 4) contends that "it is hard to exaggerate on the importance 
of a skilled facilitator". Online teaching and learning literature is inconclusive as to exactly what the role and functions of the moderator entail. Furthermore, just how much intervention from the moderator is acceptable without he/she taking over the direction of the discussion is a question. Needless to say that this dilemma is not peculiar to CMC. More that 20 years of f2f educational approaches embracing teaching and learning strategies that place emphasis on learnerdirected classroom discourse have not resolved issues related to facilitator roles and functions. Problem-based learning (PBL) literature, for instance, is indicative of this observation (Albanese \& Mitchell, 1993; Kaufman \& Holmes, 1993). To which it can be concluded that there can be no universal rules regarding the amount of facilitator intervention that is appropriate in teaching/learning settings. Contextual issues such as the level the facilitator's experience with facilitating learning, as well as the nature of substantive knowledge of the discipline concerned will determine just how much facilitator intervention is appropriate. The same can be said for online learning. In the present course, the moderator played a very active role, albeit in the form of posing questions rather than lecturing. Questions aimed at helping students analyze their meaning perspectives, authors' frames of reference, and therefore apply a more critical outlook toward literature helped improve the level of students' contributions.

\section{Lack of Closure and Feelings of not Being Heard}

It became clear early on, that we were never going to offer all the "content" that we were used to offer in the f2f course. In the CMC environment, it took too long to arrive at 'closure' on discussion of any one particular theme. Ordinarily, in a f $2 f$ classroom, a particular theme or topic is scheduled for a specific lecture period. More often than not, whether clarity and/ or resolution has been attained, the discussion moves on to the next theme, or topic. Perhaps there is an unwritten code of practice in conventional classrooms, which allows participants to let go and move on to new themes and issues for discussion in recognition of the fact that some issues can never be resolved no matter how much discussion or time is spent on them.

This was not easy to do in the present CMC course. Often we carried one week's activities to the following week, simply because there was a feeling that the discussion was nowhere near closure. At the "end" of each week or two weeks depending on how much time was initially scheduled for learning ac- tivities, the moderator compiled a summary of the week's discussion, highlighting areas which were left unresolved, lost or ignored opportunities for responding to critical questions raised by a colleague, as well as areas which were seen as indicative of misconceptions and or misinterpretations. Because the misconceptions were not "corrected" for the students but were simply highlighted, together with reasons why they were seen as such, the students raised concerns that they were left without a forum on which to test their new understandings of the issues under discussion. In fact during the initial chat session students reported that they had perpetual feelings of never "completing" learning tasks. The same feelings were experienced by the moderator. Furthermore, because the main bulletin became flooded with too many messages it became very difficult to keep track of the various points of view. Hence, some students felt that they were not being listened to. Pincas (1999) reported a similar problem with her online courses.

A number of structural changes were made to try and deal with these problems. In order to achieve some sense of closure without necessarily spending "too much" time on the same topic two changes were made. Firstly, the chat facility instead of the private mail was used as a working space for smaller groups of students. WebCT has five chat rooms, four of which allow for recording of the conversation. Each small group was allocated one of these rooms. The small groups could then work in this relatively 'public' area before posting their work in the main bulletin. Secondly, at the end of each theme or unit a whole class chat session was scheduled. This served as a forum for clarifying issues as well as obtaining some sense of "closure" on individual themes. Students responses to this change have been very positive. They have actually stated that they prefer the synchronous to the asynchronous session. This, however, does not mean that the synchronous sessions did not create their own set of problems.

The problems reported by Pincas (1999) regarding turn taking in conversation were exaggerated in the first chat session. It seemed that each student came "in" with own agenda rather than the agreed upon agenda. Managing such situations required a balance between being too directing or allowing for a completely "uncontrollable" situation. Subsequently, the students realised that if they were to benefit from synchronous discussions it was important to keep to the planned agenda and only venture to "new" topics if and only if time permits. Issues of importance to the whole group could then be scheduled for a subsequent chat session. In addition, a conscious effort is made to make sure that each student is responded to at least every other week. That is, in compiling the summary, the excerpts used as examples from the discussion to highlight a point, are chosen deliberately both for content and making students aware that they are being "listened" to.

\section{Conclusion}

In conclusion, online teaching and learning has been an invaluable experience for me. I am not sure what the future holds in terms of graduate student enrollment in South Africa. The current economic climate is not very encouraging. It seems, therefore, that residential higher education for adult students is soon becoming a thing of the past. Lessons learned from this year's course have been very helpful in planning changes for the present as well as subsequent online courses. Essentially, conscious and deliberate inclusion of every student is a must. No student wants to complete a whole semester course without ever having been referred to 'in name' by the teacher, contrary to popular beliefs about maturity and self-dependence. Furthermore, lack of adequate facilities should not be an impediment to designing and delivering CMC courses. Teachers and students need to learn to make the most of what is available to them. This is more true for deveioping countries where lack of 'sophisticated" conferencing systems is a norm rather than an exception. Lastly, the role of the moderator in CMC cannot be overly emphasized. Skilled questioning and sensitivity to "interpersonal' relations are essential for effective online teaching and learning. 


\section{References}

ALBANESE, M. A., \& MITCHELL, S. 1993. Problem-based learning: a review of literature on its outcomes and implementation issues. Academic Medicine, 68(1), $52-81$.

ANDERSON, B. 1996a. Interaction at a distance in a teacher education programme. Coursework paper for the course: Certificate in online Education and Training. London: Institute of Education, University of London.

ANDERSON, B. 1996b, JUNE. Developing interaction online. A paper presented at the Annual conference of the Distance Education Association of New Zealand in Rotorua. Also available from: Readings: Certificate in online Education and Training. London: Institute of Education, University of London.

ASTIN, A. W. 1993. Assessment for excellence: The philosophy and practice of assessment and evaluation in higher education. Phoenix, AZ: American Council on Education \& Oryx Press.

HILTZ, S. R. 1995. Teaching in a Virtual Classroom [TM]. A paper presented at an International Conference on Computer Assisted Instruction. Also available at Readings: Certificate in online Education and Training. London: Institute of Education, University of London.

KAUFMAN, D., \& HOLMES, D. B. 1996. Tutoring in problem-based learning: perceptions of teachers and students. Medical Education, 30, 371-377.

KIMBALL, L. Date unknown. Leveraging the strengths of face-to-face and groupware tools to maximise group process. Metasystems Design Group. Also available at: Readings Certificate in online Education and Training. London: Institute of Education, University of London.

PAULSEN, M. 1995. The online report on pedagogical techniques for computermediated communication. Available at $h t t p: / w w w . n k i . n o / \sim m o r t e n$.

PINCAS, A. 1999. Features of online discourse for education. Coursework Readings for the course: Certificate in online Education and Training. London: Institute of Education, University of London.

REBHOLZ, N. 1995, AUGUST. Using computer conferencing in an engineering continuing education course. Coursework paper for the course: Certificate in online Education and Training. London: Institute of Education, University of London.

SMITH, A. 1999. The use of computer mediated communication for a course on leadership and team development using action learning methodology. Coursework paper for the course: Certificate in online Education and Training. London: Institute of Education, University of London.

TUROFF, M. 1995. Designing a virtual classroom. [TM]. A paper presented at the 1995 Internal Conference Computer Assisted Instruction. Also available at Readings: Certificate in online Education and Training. London: Institute of Education, University of London.

WESTWELL, G. 1999. Computer mediated conferencing and student-centred learning at Preston College: the potential for learning communities. Coursework paper for the course: Certificate in online Education and Training. London: Institute of Education, University of London. 